\title{
Alcohol and Sexual Risk Behavior among Migrant Female Sex Workers and Male Workers in Districts with High In-Migration from Four High HIV Prevalence States in India
}

\author{
Ravi K. Verma $\cdot$ Niranjan Saggurti $\cdot$ \\ Ajay K. Singh · Suvakanta N. Swain
}

Published online: 24 June 2010

(C) Springer Science+Business Media, LLC 2010

\begin{abstract}
This paper examines the association between alcohol use and sexual risk in two critical migrant populations living within the same geographical areas-migrant men and female sex-workers (FSWs). Data are drawn from two independent surveys of migrant FSWs and male workers in 14 districts of four high HIV prevalent Indian states. In the paper we have examined the independent effects of degree of mobility and alcohol use prior to sex on HIV risk behaviors. Nearly two-thirds of FSWs and a similar proportion of male migrant workers, as well as nine out of ten clients of FSWs consume alcohol. More than half of the FSWs and their clients consumed alcohol prior to sex. The practice of alcohol use prior to sex among both FSWs and their clients has a significant association with inconsistent condom use during paid as well as unpaid sex, and these effects are independent of degree of mobility. The results suggest a need for developing an in-depth understanding of the role of alcohol in accentuating HIV risk particularly among migrant populations who move frequently from one place another.
\end{abstract}

Keywords Male migrant workers · Female sex workers . Alcohol use - Sexual risk · HIV risk · Mobility

R. K. Verma $(\varangle)$ - A. K. Singh

International Center for Research on Women,

C-139, Defence Colony, New Delhi 110024, India

e-mail: rverma@icrw.org

N. Saggurti $\cdot$ S. N. Swain

Population Council, New Delhi, India

\section{Introduction}

Both alcohol use and mobility increasingly are identified as major factors associated with enhanced sexual risk contributing to HIV. Individuals with drinking behavior are more likely to have casual sex without condoms [1,2], engage in transactional sex [3] and have more concurrent sex partners resulting in risk for HIV [4-6] and they are more likely to be HIV positive [7, 8]. At the same time, studies examining the role of migration or mobility on sexual risk behaviors show that men who are occupationally mobile are more likely to have one or more nonspousal sexual partners in the last 1 year than those who are not [2, 9-13]. Further, married migrant men who live away from their spouses are more likely to seek contacts with commercial female sex workers (FSWs), and become infected with HIV and other STIs/, than those living with their families [2, 9, 14].

Though alcohol and mobility separately have been found to affect sexual risk and HIV infection, there are few studies that have focused on assessing the combined impact of mobility and alcohol use on sexual risk behavior. Better understanding of the association of sexuality and alcohol use among migrant populations will help in developing effective multilevel approaches to mitigate the effects of this combination of risk factors.

Evidence suggests that highly mobile male migrants are more likely to engage in greater sexual risk behavior than those who are less mobile and to constitute the majority of the clients of FSWs [9, 14]. This paper examines the association between alcohol use and sexual risk in two high risk migrant populations within the same geographic areas-migrant men and mobile FSWs. We have selected a random sample of migrant men and FSWs who have been living in the current places of destinations for less than 
2 years and are highly mobile, as defined by more than one move outside their current places of destination in the past 2 years prior to the survey. Choosing samples from the same geographical area allows us to explore the potential concordance of risky behavior between male migrant workers and FSWs as well as role of alcohol in such risky behaviors.

The analysis for the present paper is built around the following key questions: (a) Are those who consume alcohol more likely to engage in sexual risk behaviors than those who do not among both migrant FSWs and male workers; and (b) Is risk further elevated for the sub-set of male clients of FSWs due to the consumption of alcohol prior to sex? To answer these questions we have assessed risk behavior patterns as they relate to alcohol use separately for the FSWs, male migrants and a subset of male migrants who reported having sex with FSWs.

\section{Methodology}

\section{Study Settings, Recruitment and Sampling}

Data used in this study are derived from two separate surveys conducted independently among FSWs and male migrant workers from June 2007 to September 2008 as part of a study titled "Migration/Mobility and Vulnerability to HIV Among Male Migrant Workers and FSWs in High HIV prevalence States in India" funded by Avahan, Bill and Melinda Gates Foundation (BMGF), New Delhi. The participants were recruited from districts across four states in southern (Andhra Pradesh, Karnataka, Tamil Nadu) and western (Maharashtra) India, identified as high epidemic states by the Indian National AIDS Control Organization (NACO, 2006) [15]. The districts with the highest rates of in-migration in each state, as indicated by the 2001 Indian census were chosen for the male migration survey $(n=21$ districts; 5 districts each in the states of Andhra Pradesh, Karnataka and Maharashtra; six districts in Tamil Nadu. For the survey of FSWs, the districts with more than 2,000 FSWs were chosen ( $n=22$ districts; 5 districts each in the states of Andhra Pradesh, Karnataka and Tamil Nadu; 7 districts in Maharashtra). This method of district selection resulted in a subsample of districts common to both male migrant workers and FSWs ( $n=14$ districts; 3 districts in Andhra Pradesh, 3 districts in Karnataka; 3 districts in Tamil Nadu and 5 districts in Maharashtra). In this paper, we focused on this subsample of 14 districts where both migrant FSWs and male workers are high in volume.

The survey samples for each group were identified and recruited following different protocols. Male migrant workers in each district were recruited through a two-stage systematic sampling procedure conducted in selected worksites and migrant worker residential colonies (either organized labor colonies or illegally occupied land with small, poor quality houses). Geographic maps drawn for each district were used to list all migrant worker residential areas and worksites and to define and select clusters within these sites. Clusters were created by combining smaller sites and dividing larger sites such that each cluster represented an area with approximately 5,000 male migrant workers. The number of clusters varied from a minimum 5 to a maximum of 13 . Three clusters were then selected randomly from within each district, and migrant men within the chosen clusters were systematically sampled to obtain a minimum of 2,500 participants per state. The sample size was determined using an estimated proportion of $15 \%$ of men having sex outside marriage, an assumed difference of $3 \%$ increase in the proportion with every unit increase in degree of mobility, a confidence level of $95 \%$ and power of $80 \%$. Eligibility criteria for inclusion in the study were age 18 years or older, and having migrated to at least two places in the past 2 years for work from among those who satisfied the inclusion criteria, a total of 11,635 male migrant workers from 21 districts across the four states were sampled. Of these, $145(1.2 \%)$ men refused to be interviewed, and $271(2.3 \%)$ men did not complete their interviews and were thus excluded from the analyses, giving us a final sample size of 11,219.

Female sex workers in each district were recruited through a two-stage sampling procedure. First, the small and large sex worker sites, including brothel areas and open solicitation points such as roads, highways, bus stands, railway stations, and market areas were mapped. These lists of solicitation sites were used to define and select site clusters. Clusters were formed by combining small areas or by segmenting the large areas such that each cluster included approximately 500 FSWs. Three such clusters from each district were selected randomly, and FSWs were systematically sampled from the brothel areas and from open solicitation points to obtain a minimum of 1,500 eligible participants per state. Eligibility criteria included: those age 18 years or older and having moved to at least two places in the past 2 years for sex work. The sample size was determined using an estimated proportion of $30 \%$ non-condom use, an assumed difference of $3 \%$ increase in the proportion with every unit increase in degree of mobility, a confidence level of $95 \%$ and power of $80 \%$. In order to achieve the desired sample size, a much larger number of female-workers was contacted and screened using the eligibility criteria. Across the entire study 9,475 sex workers were screened with a screening questionnaire. From the screened sample, $59 \%(n=5,611)$ were found eligible according to the criteria described above. Approximately 113 sex workers refused or did not complete the 
interview because of the demands of their clients. This process generated a final study sample of FSWs of 5,498.

In this paper, we focus on both migrant FSWs and male workers from the same geographic region of 14 districts resulted into a total migrant FSWs sample of 3,412 and male workers sample of 7,602 for statistical analyses. There were no significant differences in socio-demographics and mobility characteristics between this subsample from 14 districts and participants from the remaining districts.

Interviews were conducted by trained researchers with multilingual expertise. All the researchers had at least 5 years of experience and a graduate and masters degree in sociology, anthropology and/or statistics. Data were obtained through face-to-face interviews conducted in private locations close to the respondent's residence or at their workplace. Verbal consent was obtained from all respondents before they were interviewed. Data quality control and management involved immediate review by field staff after interviews to ensure accuracy and completion, sameday review by the field supervisor and weekly transport of surveys to the data management team. Trained data entry officers then entered the survey data weekly and processed it monthly to verify consistency and accuracy, using SPSS (SPSS Version 16.0). Ethical approval for the study was obtained from the Institutional Review Board (IRB) of the Population Council, New York, USA.

\section{Measures}

Socio-demographic assessments for male and female participants were similar with the same variables being used to assess participant age, level of education, marital status, whether or not male migrants were currently residing with their wives, caste and religion. The occupation of the male migrant workers was captured under the following categories: construction work, market place loading and unloading, daily wage work, industrial work, stone cutting, and fishing. Information on participants' marital status and partners' residential status was combined to derive a variable with categories: "currently married and living with spouse in destination area $=1$ "; "currently married and partner at the place of origin $=2$ ", "not currently married $=3$ " For the current study, divorced, widowed, separated and deserted were combined and the category was named as 'previously married'.

The survey also collected information on caste. For the current study the items 'Scheduled Caste and Scheduled Tribes' were clubbed together to create three categories, 'Scheduled caste/tribe', 'OBC' and 'Others' (representing upper cast designations).

The survey instrument assessed the type of alcohol used at the place of destination in the 1 month period prior to the survey (past 30 day use). Type of alcohol included Beer, English liquor (whisky, brandy, rum) and desi (country) liquor. Responses were "Yes $=1$ " or "No $=0$ ". We used any past 30 day alcohol use as a predictor of the sexual behavior of participants. The survey instrument also collected information on alcohol use prior to or during sex with a paying partner, and non-spousal casual unpaid partner. Alcohol use prior/during sex with either partner constituted the primary independent variable for assessing the key outcome indicators of HIV related risk behavior.

Degree of mobility, another key independent variable was derived from the survey item that asked how many different places the respondent visited in the past 2 years for work related purposes. Those indicating fewer than three places were coded as " 0 , lower mobility" and those indicating three or more places were coded as " 1 , high mobility".

The sexual risk outcome variables focused on sex with partners in the place of destination and included sex with paid female partners, number of paid sex partners, number of paid sexual encounters, sex with casual female partners, number of non-paying sex partners, consistent condom use in sex with paid female partners, consistent condom use with casual female partners. For male migrant workers the recall time period was past 12 months, and for FSWs the recall time period was past 1 week. Five sexual outcome variables were dichotomized (a) whether the male and female participants had sex with paying partner (yes $=1$, no $=0$ ), (b) whether they had sex with nonpaying partner (yes $=1$, no $=0$ ), (c) whether they had sex with either partner (yes $=1$, no $=0$ ), (d) whether they had sex with both paying and non-paying partner (yes $=1$, no $=0)$, (e) whether they had sex with more than three partners (yes $=1$, no $=0$ ).

\section{Analysis}

Data were analyzed separately for the samples of FSWs $(n=3,412)$ and male migrant workers $(n=7,602)$ from the 14 districts common to both to assess the role of alcohol in relation to sexual risk. Additionally, the data for the subsample of male migrant workers who were clients of FSWs $(n=1,103)$ were also analyzed in order to determine whether there were commonalities in the patterns of alcohol consumption and sexual risk for clients and FSWs interacting in the same districts. Thus, we are conducting two levels of comparison: (1) comparing male and female workers living within the same geographical areas, and (2) comparing male clients of FSWs with the FSWs and the total sample of migrant men from the same area.

Descriptive statistics were obtained for demographic variables, covariates and the independent and dependent 
variables in the study. $t$ Tests and Chi-square analyses were conducted to assess differences between independent and dependent variables. A series of multiple logistic regression models were generated, first to explore the effects of mobility on alcohol use, then to examine the effects of alcohol use on sexual behaviors, and finally, to determine the effects of alcohol use prior to sex on sexual risk behaviour.

\section{Results}

\section{Participant Characteristics}

Results in Table 1 show that the average age of FSWs was 30 years [standard deviation $(\mathrm{SD})=7.4)$ and the male migrant workers was 26.5 years $(\mathrm{SD}=5.5)$. More migrant FSWs than the male workers were illiterate (31.4 vs. $14.7 \%, t=18.7, p<0.001)$. About one-fourth of male migrant workers were currently married and the spouse was living at the place of origin, an additional $25 \%$ were living with spouse at the place of destination and about $49 \%$ were unmarried. Among clients of FSWs, the proportion of unmarried respondents was somewhat higher than the total sample of male migrant workers (54.2 vs. $48.6 \%, t=3.48$, $p<0.05)$. Approximately two-thirds of migrant FSWs and one-third of male workers had moved to three or more places in the past 2 years for work purposes (met "high mobility" criterion). More clients of FSWs fall into the "high mobility" category than the total sample of male migrant workers in the study districts $(47.3$ vs. $36.9 \%$, $t=6.49, p<0.001$.

\section{Alcohol Use}

Compared with the total sample of male migrant workers, the proportion of clients of FSWs who reported drinking any alcohol (88 vs. 66.2\%, $t=19.5, p<0.001$, and drinking all types of alcohol in the past 30 days (22.8 vs. $13 \%, t=7.42, p<0.001$ is significantly higher than those who did not report visiting FSWs. A similar proportion of FSWs (53.8\%) and clients of FSWs (52.8\%) reported alcohol use prior to sex.

\section{Sexual Risk Behavior}

Almost all the FSWs reported having sex with paying partners in the last week prior to the survey. About $15 \%$ of the total sample of male migrant workers reported sex with FSWs in the last 12 months prior to the survey. The average number of paying partners for FSWs in the past week was fifteen $(S D=10)$, whereas for male migrant workers in the past year it was four $(\mathrm{SD}=6.0)$. Approximately one-third of the FSWs and the male migrant workers reported inconsistent condom use in sex with paying partners in case of FSWs and paid partners in case of male migrants (34.7 and 33.9\%, respectively).

Approximately half of the total FSWs reported sex with non-paying partners in the week prior to the survey. In the total sample of male migrant workers $16 \%$ reported sex with unpaid partners in contrast to $45 \%$ among clients of FSWs. Inconsistent condom use in sex with unpaid partners is high in all three groups, FSWs (60.1\%), all male migrant workers $(79.7 \%)$ and clients of FSWs $(65 \%)$.

\section{Degree of Mobility and Alcohol Use}

Table 2 shows the relationships between degree of mobility and alcohol use among both migrant FSWs and male workers. We note that higher mobility has very little association with alcohol use among the FSWs; but among the male migrant workers in both groups, the effects of higher mobility on alcohol use are significant. Alcohol use among male migrant workers with high degree of mobility is higher than the male migrant workers with low degree of mobility $[77$ vs. $60.1 \%$, adjusted odds ratio $(\mathrm{AOR})=2.1,95 \%$ confidence interval $(\mathrm{CI})=1.8-2.3$ ]. The results also suggest that FSWs with higher mobility than those with lesser mobility are less likely to consume all different types of alcohol brands $(22.6$ vs. $18.9 \%, \mathrm{AOR}=0.7,95 \% \mathrm{CI}=$ $0.6-0.8)$. On the contrary, the male migrant workers with higher mobility are more likely to drink all the types of alcohol brands $(7.7$ vs. $22.1 \%$, AOR $=3.4,95 \% \mathrm{CI}=$ 2.9-3.9) when compared to those men with lesser mobility.

Also, as shown in Table 2, alcohol use prior to sex is significantly higher in highly mobile male migrant workers in the total sample $(10$ vs. $6.6 \%, \mathrm{AOR}=1.5,95 \%$ $\mathrm{CI}=1.2-1.7)$, but not for clients of FSWs where there is no difference between highly mobile and less mobile men.

\section{Alcohol Use and Sexual Behavior}

Table 3 shows that among the FSWs alcohol use has a significant association with having a non-paying male partner and having sex with more than three partners per day. In the total sample of male migrant workers, alcohol users report higher rates of contact with sex workers than non-users (19.2 vs. $5.1 \%$, $\mathrm{AOR}=4.9,95 \% \mathrm{CI}=4.0-5.9$ ). The proportion of male migrant workers reporting sex with unpaid partners is also higher among alcohol users than among the non-users (22.1 vs. $5.9 \%, \mathrm{AOR}=4.7,95 \%$ $\mathrm{CI}=3.9-5.6)$ and among clients of FSWs (47 vs. $28.8 \%$, 
Table 1 Characteristics of female sex workers, male migrant workers for total sample and a sub-sample of those reported sex with female sex workers from selected states of India

\begin{tabular}{|c|c|c|c|}
\hline \multirow[t]{2}{*}{ Demographic characteristics } & \multirow{2}{*}{$\begin{array}{l}\text { Female sex workers } \\
n=3,412 \\
n(\%)\end{array}$} & \multicolumn{2}{|c|}{ Male migrant workers } \\
\hline & & $\begin{array}{l}\text { Total sample } \\
n=7,620 \\
n(\%)\end{array}$ & $\begin{array}{l}\text { Clients of FSWs } \\
n=1,103 \\
n(\%)\end{array}$ \\
\hline Age [mean (SD)] & $30.0(7.4)$ & $26.5(5.6)$ & $26.5(5.1)$ \\
\hline \multicolumn{4}{|l|}{ Education } \\
\hline Illiterates & $1,073(31.4)$ & $1,122(14.7)$ & $145(13.1)$ \\
\hline Literates & $2,339(68.6)$ & $6,498(85.3)$ & $958(86.9)$ \\
\hline \multicolumn{4}{|l|}{ Religion } \\
\hline Hindu & $2,590(75.9)$ & $6,448(84.6)$ & $903(81.9)$ \\
\hline Others & $822(24.1)$ & $1,172(15.4)$ & $200(18.1)$ \\
\hline \multicolumn{4}{|l|}{ Marital status } \\
\hline Currently married living with spouse & NA & $1,930(25.4)$ & $202(18.3)$ \\
\hline Currently married but spouse is at native place & NA & $1,985(26.0)$ & $303(27.5)$ \\
\hline Unmarried & $555(16.3)$ & $3,705(48.6)$ & $598(54.2)$ \\
\hline Currently Married & $1,243(36.4)$ & NA & NA \\
\hline Previously Married & $1,614(47.3)$ & NA & NA \\
\hline \multicolumn{4}{|l|}{ Caste } \\
\hline Scheduled caste/tribe & $1,126(33.0)$ & $3,107(40.8)$ & $502(45.5)$ \\
\hline Others (11 cases missing) & $1,760(51.6)$ & $4,502(59.2)$ & $598(54.2)$ \\
\hline \multicolumn{4}{|l|}{ Degree of mobility } \\
\hline Less mobility ( $<3$ places) & $1,146(33.6)$ & $4,803(63.1)$ & $581(52.7)$ \\
\hline High mobility $(3+$ places $)$ & $2,266(66.4)$ & $2,817(36.9)$ & $522(47.3)$ \\
\hline \multicolumn{4}{|l|}{ Alcohol use in the last 1 month } \\
\hline Any alcohol intake ${ }^{a}$ & $2,115(62.0)$ & $5,048(66.2)$ & $971(88.0)$ \\
\hline All types of alcohol ${ }^{\mathrm{b}}$ & $662(19.4)$ & $988(13.0)$ & $251(22.8)$ \\
\hline Alcohol use prior to $\mathrm{sex}^{\mathrm{c}}$ & $1,835(53.8)$ & $951(12.5)$ & $582(52.8)$ \\
\hline Injecting drug use & $22(0.6)$ & $41(0.5)$ & $3(0.3)$ \\
\hline \multicolumn{4}{|l|}{ Sexual behavior in the place of destination } \\
\hline Sex with paying partners ${ }^{\mathrm{d}, \mathrm{f}}$ & $3,408(99.9)$ & $1,103(14.5)$ & $1,103(100.0)$ \\
\hline Average number of paying sex partners $(\mathrm{SD})^{\mathrm{d}, \mathrm{f}}$ & $15.4(10.5)$ & $4.1(6.0)$ & $4.1(6.0)$ \\
\hline Average number of paying sex encounters $(\mathrm{SD})^{\mathrm{e}, \mathrm{f}}$ & $5.1(3.2)$ & $8.2(9.5)$ & $8.2(9.5)$ \\
\hline Inconsistent condom use in sex with paying partners ${ }^{\mathrm{a}}$ & $1,185(34.7)$ & $374 / 1,103(33.9)$ & $374 / 1,103(33.9)$ \\
\hline Sex with casual, non-paying partners & $1,550(45.4)$ & $1,267(16.6)$ & $496(45.0)$ \\
\hline Average number of non-paying sex partners $(S D)^{d, f}$ & $2.1(1.5)$ & $1.9(3.1)$ & $2.6(4.5)$ \\
\hline Average number of non-paying sex encounters $(\mathrm{SD})^{\mathrm{e}, \mathrm{f}}$ & $\mathrm{n} / \mathrm{a}$ & $8.1(12.4)$ & $9.5(14.2)$ \\
\hline Inconsistent condom use in sex with non-paying, casual partners & $931 / 1,550(60.1)$ & $1,010 / 1,267(79.7)$ & $326 / 496(65.7)$ \\
\hline Sex with both paying and non-paying/casual partners & $1,020(29.9)$ & $496(6.5)$ & $496(45.0)$ \\
\hline Sex with either paying or non-paying/casual partners & $3,412(100.0)$ & $1,874(24.6)$ & $1,103(100.0)$ \\
\hline Overall inconsistent condom use & $1,995 / 3,412(58.5)$ & $1,052 / 1,874(56.1)$ & $368 / 1,103(33.4)$ \\
\hline Sex with $3+$ sex partners ${ }^{e, f}$ & $2,240(65.7)$ & $945(12.4)$ & $816(74.0)$ \\
\hline
\end{tabular}

$S D$ Standard deviation

a Any of the following types of alcohol use in the 1 month prior to survey: beer, English liquor (whisky, brandy, rum, gin), desi (country) liquor

b Has taken all the following types of alcohol: beer, English liquor (whisky, brandy, rum, gin), desi (country) liquor

c Alcohol use prior to sex with either partner

d Per week for sex workers

e Per day for sex workers

${ }^{\mathrm{f}}$ In the last 12 months for male migrant workers 
Table 2 Association between mobility and alcohol use among female sex workers, male migrant workers for total sample and a sub-sample of those reported sex with female sex workers

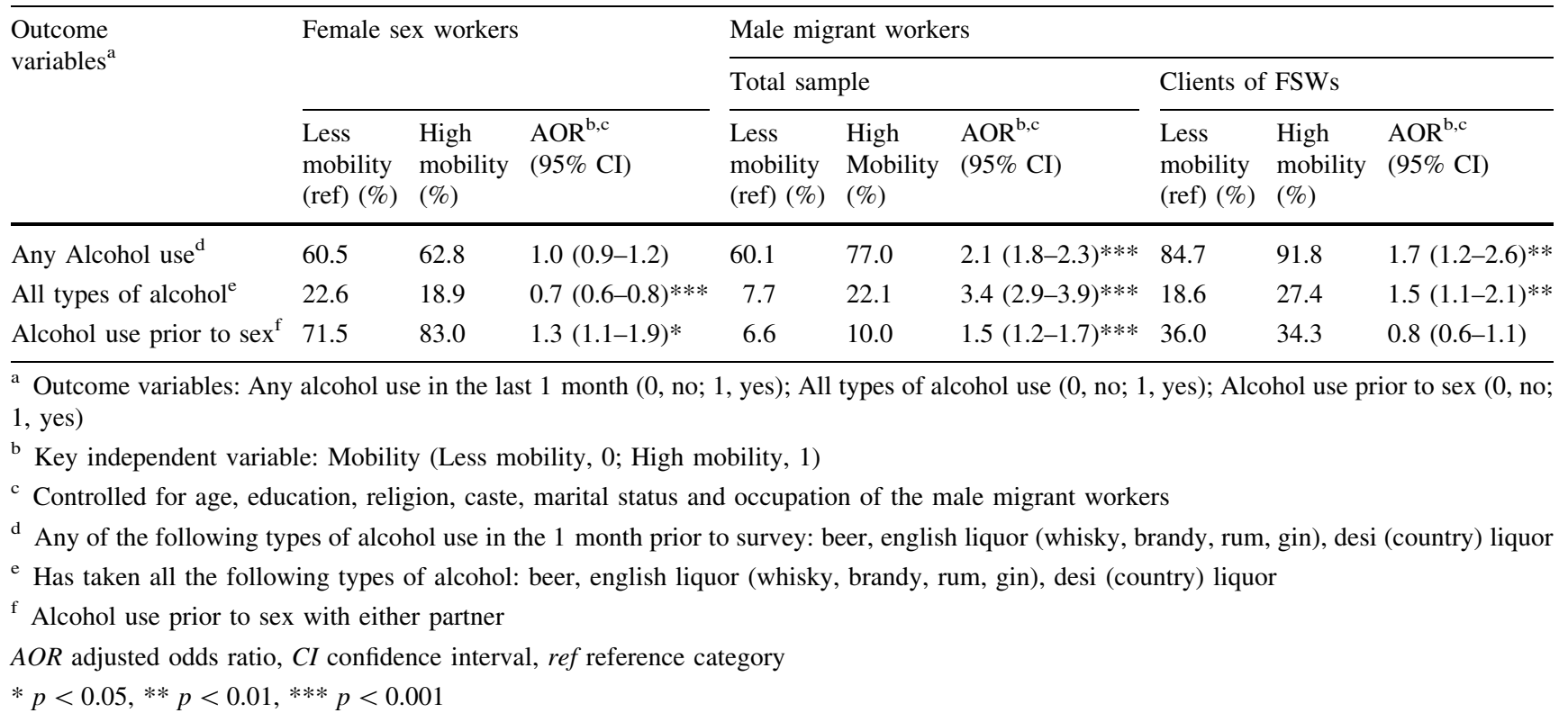

Table 3 Association between alcohol use and sexual behaviors among female sex workers, male migrant workers for total sample and a subsample of those reported sex with female sex workers

\begin{tabular}{|c|c|c|c|c|c|c|c|c|c|}
\hline \multirow[t]{3}{*}{ Outcome variables $^{\mathrm{a}}$} & \multirow{2}{*}{\multicolumn{3}{|c|}{ Female sex workers }} & \multicolumn{6}{|c|}{ Male migrant workers } \\
\hline & & & & \multicolumn{3}{|c|}{ Total sample } & \multicolumn{3}{|c|}{ Clients of FSWs } \\
\hline & $\begin{array}{l}\text { No } \\
\text { alcohol } \\
(\%)\end{array}$ & $\begin{array}{l}\text { Yes } \\
\text { alcohol } \\
(\%)\end{array}$ & $\begin{array}{l}\mathrm{AOR}^{\mathrm{b}, \mathrm{c}} \\
(95 \% \mathrm{CI})\end{array}$ & $\begin{array}{l}\text { No } \\
\text { alcohol } \\
(\%)\end{array}$ & $\begin{array}{l}\text { Yes } \\
\text { alcohol } \\
(\%)\end{array}$ & $\begin{array}{l}\mathrm{AOR}^{\mathrm{b}, \mathrm{c}} \\
(95 \% \mathrm{CI})\end{array}$ & $\begin{array}{l}\text { No } \\
\text { alcohol } \\
(\%)\end{array}$ & $\begin{array}{l}\text { Yes } \\
\text { alcohol } \\
(\%)\end{array}$ & $\begin{array}{l}\mathrm{AOR}^{\mathrm{b}, \mathrm{c}} \\
(95 \% \mathrm{CI})\end{array}$ \\
\hline Sex with paying partner ${ }^{\mathrm{f}}$ & - & - & & 5.1 & 19.2 & $4.9(4.0-5.9)^{* * *}$ & - & - & \\
\hline $\begin{array}{l}\text { Sex with non-paying/casual } \\
\text { partner,f }\end{array}$ & 24.4 & 33.3 & $1.5(1.3-1.8)^{* * *}$ & 5.9 & 22.1 & $4.7(3.9-5.6)^{* * *}$ & 28.8 & 47.2 & $1.9(1.2-2.8)^{* *}$ \\
\hline Sex with either partner ${ }^{\mathrm{f}}$ & - & - & & 9.5 & 32.3 & $5.0(4.3-5.8)^{* * *}$ & - & - & \\
\hline $\begin{array}{l}\text { Sex with both paying and } \\
\text { non-paying/casual } \\
\text { partner }^{\mathrm{d}, \mathrm{f}}\end{array}$ & 24.4 & 33.3 & $1.5(1.3-1.8)^{* * *}$ & 1.5 & 9.1 & $6.5(4.6-9.1)^{* * *}$ & 28.8 & 47.2 & $1.9(1.2-2.8)^{* *}$ \\
\hline Sex with $3+$ partners ${ }^{e, f}$ & 62.6 & 67.5 & $1.2(1.1-1.5)^{* * *}$ & 3.1 & 12.9 & $5.1(4.0-6.5)^{* * *}$ & 56.8 & 62.2 & $1.4(0.9-1.9)$ \\
\hline
\end{tabular}

a Outcome variables: Sex with paying partner ( 0, no; 1 , yes), sex with non-paying partner ( 0 , no; 1 , yes), sex with either paying or non-paying partner $(0$, no; 1 , yes), sex with both paying and non-paying partner $(0$, no; 1 , yes), sex with $3+$ partners $(0$, no; 1 , yes $)$

${ }^{\mathrm{b}}$ Key independent variable: Any alcohol use in the last 1 month (No, 0; Yes, 1)

${ }^{c}$ Controlled for age, education, religion, caste, marital status and occupation of the male migrant workers

d Per week for sex workers

e Per day for sex workers

${ }^{\mathrm{f}}$ In the last 12 months for male migrant workers

$A O R$ adjusted odds ratio, $C I$ confidence interval, ref reference category

$* p<0.05, * * p<0.01, * * * p<0.001$

$\mathrm{AOR}=1.9,95 \% \mathrm{CI}=1.2-2.8)$. The proportion of total male migrant workers who reported sex with both paid and unpaid partners $n$ the last year prior to the survey was significantly higher among alcohol users than among the non-users (9.1 vs. $1.5 \%, \mathrm{AOR}=6.5,95 \% \mathrm{CI}=4.6-9.1)$. This association was also significant for FSWs $(\mathrm{AOR}=$ $1.5,95 \% \mathrm{CI}=1.3-1.8$ ) and for clients of FSWs (AOR 1.9, $95 \% \mathrm{CI}=1.2-2.8)$. 
Table 4 Association between mobility, alcohol use prior to sex and inconsistent condom use among male migrant workers for total sample and a sub-sample of those reported sex with sex workers in India

\begin{tabular}{|c|c|c|c|c|c|c|}
\hline \multirow[t]{2}{*}{ Outcome variables $^{\mathrm{a}}$} & \multicolumn{3}{|c|}{ Alcohol use prior to sex ${ }^{\mathrm{d}}$} & \multicolumn{3}{|c|}{ Degree of mobility } \\
\hline & $\begin{array}{l}\text { No (ref) } \\
(\%)\end{array}$ & $\begin{array}{l}\text { Yes } \\
(\%)\end{array}$ & $\begin{array}{l}\mathrm{AOR}^{\mathrm{b}, \mathrm{c}} \\
(95 \% \mathrm{CI})\end{array}$ & $\begin{array}{l}\text { Less (ref) } \\
(\%)\end{array}$ & $\begin{array}{l}\text { High } \\
(\%)\end{array}$ & $\begin{array}{l}\mathrm{AOR}^{\mathrm{b}, \mathrm{c}} \\
(95 \% \mathrm{CI})\end{array}$ \\
\hline \multicolumn{7}{|l|}{ Female sex workers } \\
\hline Inconsistent condom uses in sex with paying partners & 19.4 & 39.2 & $3.0(2.3-3.9)^{* * *}$ & 21.0 & 44.6 & $3.4(2.8-4.0)^{* * *}$ \\
\hline $\begin{array}{l}\text { Inconsistent condom use in sex with non-paying/casual } \\
\text { partners }\end{array}$ & 45.8 & 56.6 & $1.5(1.1-2.0) * * *$ & 44.2 & 64.3 & $2.1(1.6-2.8)^{* * *}$ \\
\hline Overall inconsistent condom use $\mathrm{e}^{\mathrm{e}}$ & 29.3 & 44.0 & $2.1(1.7-2.6)^{* * *}$ & 25.0 & 49.9 & $3.2(2.7-3.8)^{* * *}$ \\
\hline \multicolumn{7}{|l|}{ Male migrant workers } \\
\hline Inconsistent condom uses in sex with paying female partners ${ }^{\mathrm{f}}$ & 23.6 & 43.1 & $2.7(2.0-3.5)^{* * *}$ & 27.2 & 41.4 & $1.9(1.4-2.5)^{* * *}$ \\
\hline $\begin{array}{l}\text { Inconsistent condom use in sex with non-paying/casual } \\
\text { female partners }\end{array}$ & 80.2 & 78.7 & $0.9(0.7-1.3)$ & 74.1 & 83.9 & $2.1(1.6-2.9)^{* * *}$ \\
\hline Overall inconsistent condom use $\mathrm{e}^{\mathrm{e}}$ & 58.9 & 51.7 & $0.7(0.6-0.9)^{* *}$ & 46.6 & 65.3 & $2.1(1.7-2.6)^{* * *}$ \\
\hline \multicolumn{7}{|l|}{ Clients of female sex workers } \\
\hline Inconsistent condom uses in sex with paying female partners ${ }^{\mathrm{f}}$ & 23.6 & 43.1 & $2.7(2.0-3.5)^{* * *}$ & 27.2 & 41.4 & $1.8(1.4-2.4)^{* * *}$ \\
\hline $\begin{array}{l}\text { Inconsistent condom use in sex with non-paying/casual } \\
\text { female partners }\end{array}$ & 54.5 & 73.5 & $2.7(1.8-4.1)^{* * *}$ & 62.4 & 68.0 & $1.8(1.2-2.8)^{* *}$ \\
\hline Overall inconsistent condom use $\mathrm{e}^{\mathrm{e}}$ & 23.2 & 42.4 & $2.7(2.1-3.5)^{* * *}$ & 26.7 & 40.8 & $1.9(1.4-2.5)^{* * *}$ \\
\hline
\end{tabular}

${ }^{a}$ Outcome variable coding: Inconsistent condom use (by type of partner) (0, no; 1 , yes)

b Key independent variables: Alcohol use prior to sex (0-no, 1-yes); Degree of mobility (less-0, high-1)

c Controlled for age, education, religion, caste, marital status, occupation and the other variables in the above table

d Alcohol use prior to sex with either partner

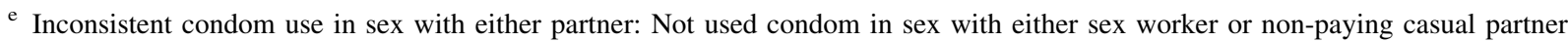

${ }^{\mathrm{f}}$ Inconsistent condom use in sex with sex worker in the past 12 months

$\mathrm{g}$ Inconsistent condom use in sex with non-paying, casual partner in the past 12 months

$A O R$ adjusted odds ratio, $C I$ confidence interval, ref reference category

$* p<0.05, * * p<0.01, * * * p<0.001$

Independent Effects of Degree of Mobility, and Alcohol Use Prior to Sex on Inconsistent Condom Use

Among FSWs, inconsistent condom use in sex with paying partners is higher among men who used alcohol prior to sex than among those who did not (39.2 vs. $19.4 \%$, $\mathrm{AOR}=3.0,95 \% \mathrm{CI}=2.3-3.9$ ) even after controlling for degree of mobility and socio-demographic characteristics. Additionally, inconsistent condom use with unpaid partners is also higher among men who consume alcohol prior to sex than among those who do not. Among male migrant workers, inconsistent condom use with paid partners is significantly higher if they consumed alcohol prior to sex than if they did not (43.1 vs. $23.6 \%, \mathrm{AOR}=2.7,95 \%$ $\mathrm{CI}=2.0-3.5)$. Among the subsample of male migrant workers who are clients of FSWs, inconsistent condom use with non-paying casual partners (73.5 vs. $54.5 \%$, $\mathrm{AOR}=2.7,95 \% \mathrm{CI}=1.8-4.1)$ is significantly higher if they used alcohol prior to sex than those who did not consume alcohol prior to sex (Table 4)
Degree of mobility is significantly associated with inconsistent condom use among FSWs as well as among the total sample of male migrant workers, and the subsample of male migrant workers who are clients of FSWs.

\section{Discussion}

The analysis of our study data shows that alcohol use among FSWs and male migrant workers is widespread. Nearly two-thirds of FSWs and male migrant workers, and nine out of ten clients of FSWs consumed at least one type of alcohol in the past 30 days, with more than half of FSWs and clients of FSWs drinking prior to sex. Among both FSWs and their clients, the practice of drinking alcohol in association with sex is significantly associated with inconsistent condom use in paid as well as unpaid sex.

Prior studies in India have reported somewhat lower levels of 30 day alcohol consumption in (high risk populations) [16, 17] compared with the current study data, 
suggesting that the alcohol use is more prevalent among migrant populations especially when involved in paid as well as unpaid sex and are thus at higher risk for HIV. Alcohol use increased with degree of mobility, suggesting the need to examine in greater depth alcohol meanings and drinking behaviors and their association with situational responses and sexuality in the lives of migrant populations who move from one place to another frequently.

This study result linking alcohol use and degree of mobility among migrant populations is the first of its kind in both India and global literature. Studies carried out in other geographical areas (mostly in North America and Africa suggest that alcohol use tends to relate with sexual risk through various psychological correlates such as sexual sensation seeking [18-21], fear of condom negotiation [22], and peer group influences [19]. Now what is important from the point of view of planning risk reduction strategies is to understand how some of these psychological correlates, particularly those relating to sensation seeking and peer group influences translate into the daily actions of mobile male migrants.

The study also shows that FSWs and clients in the same geographic area both use alcohol prior to or during sex. A gender perspective helps to understand why this might be the case. For example, a WHO study [22] linking alcohol use with sexual risk in eight countries including India also showed that there were instances when FSWs 'pretended' to use alcohol or took only small amounts prior to sex in order to maximize their potential for negotiating condom use or sex practices. Alcohol may also be used by FSWs to cope with the stress and violence associated with commercial sex work [23, 24]. At the same time, men have been reported to purchase beer before engaging in sexually risky behavior to impress women that they had money [2]. They may use alcohol to demonstrate masculinity norms and expectations and to promote a variety of sexual practices with their paid sex partners.

Increased sexual risk associated with higher rate of mobility, among men arise because they are away from home for longer time and less subject to the social controls that might be exerted in their native place. Further they may be faced with a high level of peer pressure to drink and visit FSWs. Studies among young men from similar low income migrant communities in India have shown that masculinity norms tend to result in sexually risky outcomes due to high peer pressure and need to prove their masculinity [25].

The study shows increased sexual risk within unpaid sexual encounters. Both migrant FSWs and male workers are involved in a significant number of unpaid sexual encounters during which condom use is inconsistent at best. Little is known about how these unpaid associations occur, and with whom. Inconsistent condom use is generally associated with some degree of intimacy between partners. Further, other resources exchanges in addition to monetary transactions may take place in these relationships. More research is required to understand how to address this area of high risk exposure among highly mobile migrant workers, both men and women. A gender sensitive program would help understand the relationship issues within the commercial sex context and help both the male clients and FSWs to protect themselves and at the same time care about each others' welfare.

A realistic HIV prevention program will need to promote consistent condom use and other safe sex behaviors with clear understanding of how alcohol use helps or inhibits its safe negotiation. To refine our understanding of the risk context more qualitative research is required among high risk, mobile groups, to obtain detailed information about the situations in which sexual encounters take place, through semi-structured ethnographic interviews and direct observation in selected sites, such as alcohol sales points, especially those that offer opportunities for paid or unpaid sex. This study points to the need for developing a greater in-depth understanding of the role of alcohol in accentuating the HIV risk among migrant populations with greater mobility.

Acknowledgments This study was funded by a grant from the Bill and Melinda Gates Foundation through Avahan, its India AIDS Initiative to Population Council. The views expressed herein are those of the authors and do not necessarily reflect the official policy or position of the Bill and Melinda Gates Foundation and Avahan. The authors would like to thank the organizers of the Alcohol and Sexual Risk Conference, Dr. Jean J. Schensul, Senior Researcher and Founding Director of the Institute for Community Research in Hartford, CT, USA and Dr. S. K. Singh, Associate Professor, International Institute for Population Sciences, Mumbai, India, where this paper was first presented.

\section{References}

1. Stanton M, Leukefeld C, Logan TK, Zimmerman R, Lynam D, Milich R, et al. Risky sex behaviour and substance use among young adults. Health Soc Work. 1999;24:147-54.

2. Saggurti N, Verma RK, Jain A, RamaRao S, Kumar KA, Subbiah A, Modugu HR, Halli SS, Bharat S. HIV risk behaviors among contracted and non-contracted male migrant workers in India: potential role of labor contractors and contractual systems in HIV prevention. AIDS. 2008;22(suppl 5):S1-10.

3. Kaljee LM, Genberg BL, Minh TT, Tho LH, Thoa LTK, Stanton B. Alcohol use and HIV risk behaviors among rural adolescents in Khanh Hoa Province Viet Nam. Health Educ Res. 2005;20: 71-80.

4. Dunkle KL, Jewkes RK, Brown HC, Gray GE, McIntyre JA, Harlow SD. Transactional sex among women in Soweto, South Africa: Prevalence, risk factors and association with HIV infection. Soc Sci Med. 2004;59:1581-92.

5. Mataure P, McFarland W, Fritz K, et al. Alcohol use and highrisk sexual behavior among adolescents and young adults in Harare, Zimbabwe. AIDS Behav. 2002;6(3):211-9. 
6. Zachariah R, Teck R, Humblet $P$, Harries AD. Implementing joint TB and HIV interventions in a rural district of Malawi. Is there a role for an international non governmental organization? Int J Tuberc Lung Dis. 2004;8:1058-64.

7. Campbell JC, Webster D, Koziol-McLain J, Block C, Campbell D, Curry MA, et al. Risk factors for femicide in abusive relationships: results from a multisite case-control study. Am J Public Health. 2003;93(7):1089-97.

8. Saggurti N, Schensul SL, Verma RK. Migration, mobility and sexual risk behaviour in Mumbai, India: mobile men with nonresidential wife show increased risk. AIDS Behav. 2009; 13(5):921-7.

9. Halli SS, Blanchard J, Satihal DG, Moses S. Migration and HIV transmission in rural south India: an ethnographic study. Cult Health Sex. 2007;9:85-94.

10. Rego A, Nadkarni V, Vasundhra D. HIV/AIDS in India: a critical review of selected studies (1990-2000). The gender and reproductive health research initiative. New Delhi: CREA; 2002.

11. Singh SK, Gupta K, Lahiri S, Schensul J. Dynamics of social networking, drug abuse and risk behaviour to STD and HIV/ AIDS in India: a case study of adult male migrants in Surat, India. In: Pandey A, editor. Bio-statistical aspects of health and population. New Delhi: Hindustan Publishing Corporation; 2006.

12. Vemuri MD, Bhattacharya S. Migration pattern of Uttar Pradesh's population. Calcutta: SAATHI Library; 2004.

13. Mishra A. Risk of sexually transmitted infections among migrant men: findings from a survey in Delhi. Asian Pac Migr J. 2004; 13:89-106.

14. NACO. HIV/AIDS epidemiological Surveillance \& Estimation report for the year 2005. New Delhi: National AIDS Control Organization; 2006.

15. NACO. National baseline high risk \& bridge population behavioural surveillence survey. New Delhi: National AIDS Control Organization; 2002.
16. Sivaram S, Latkin CA, Solomon S, Celentano DD. HIV prevention in India: focus on men, alcohol use and social networks. Harv Health Policy Rev. 2006;7(2):125-34.

17. Chaturvedi S, Singh Z, Banerjee A, Khera A, Joshi RK, Dhrubajyoti D. Sexual behaviour among long distance truck drivers. Indian J Community Med. 2006;31(3):153-6.

18. Brooks C, Monahan J, Sales J, DiClemente R, Wingood G, Samp JA, Rose E: Alcohol, Psychosocial Correlates, and Risky Sexual Behavior for a High-Risk African-American Female Population. Paper presented at the annual meeting of the International Communication Association, TBA, Montreal, QC, Canada, May 21, 2008

19. Weinhardt LS, Carey MP. Does alcohol lead to sexual risk behaviour? Findings from event-level research. Annu Rev Sex Res. 2000;11:125-57.

20. Kalichman SC, Weinhardt L, DiFonzo K, Austin J, Luke W. Sensation seeking and alcohol use as markers of sexual transmission risk behaviours in HIV-positive men. Ann Behav Med. 2002;24:229-35.

21. Testa M. The impact of men's alcohol consumption on perpetration of sexual aggression. Clin Psychol Rev. 2002;22:1239-63.

22. WHO. Alcohol use and sexual risk behaviour: a cross-cultural study in eight countries. Geneva: WHO; 2005. p. 99-100.

23. Samuels F, Verma RK, George CK. Stigma, discrimination and violence against female sex-workers and men who have sex with men in Andhra Pradesh. In: Minke V, editor. Gender and health. Netherlands: Institute of Social Science; 2006.

24. Population Council. Patterns of mobility and HIV risk among female sex workers and male migrant workers: Andhra Pradesh. New Delhi: Population Counicl; 2009.

25. Verma RK, Pulerwitz J, Mahendra V, Khandekar S, Barker G, Fulpagare P, Singh SK. Challenging and changing gender attitudes among young men in India. Reprod Health Matters. 2006;14(28):1-10. 